\title{
Disagreement, correctness, and the evidence for metaethical absolutism ${ }^{1}$
}

\author{
Gunnar Björnsson \\ Umeå University, University of Gothenburg
}

Metaethical absolutism, or just absolutism, is the view that moral concepts have non-relative satisfaction conditions that are constant across judges and their particular beliefs, attitudes, and cultural embedding. Absolutism is compatible with a variety of more widely discussed views about moral semantics - descriptivist and non-descriptivist, naturalist and non-naturalist, realist and constructivist - but it arguably has more practically important consequences than either of these. If absolutism is true, there is an important sense in which parties of moral disputes are concerned to get the same things right, such that their disputes can be settled by the facts. If it is not true, as various forms of relativism and non-cognitivism imply, such coordination of concerns will be limited. ${ }^{2}$

The most influential support for absolutism comes from two related premises. According to the first, moral thinking and moral discourse display a number of features that are characteristically found in paradigmatically absolutist domains, and only partly in uncontroversially non-absolutist domains. Among these features, we find ways of thinking about moral disagreement, and ways of attributing correctness to moral judgments. According to the second premise, the best way of making sense of these features is to assume that absolutism holds for this domain. Moral thinking and discourse display a certain unity that would be less straightforwardly explained if forms of metaethical relativism or non-cognitivism were true. ${ }^{3}$

One can object to this argument from unity in two ways. One might reject the first premise, denying that morality displays "absolutist" patterns of disagreement. Or one might

${ }^{1}$ I am grateful for feedback from audiences at the University of Connecticut, University of Gothenburg, University of Edinburgh, Lund University, Umeå University, the $9^{\text {th }}$ Wisconsin Metaethics Workshop, and the Values in Context workshop at the University of Lisbon. Special thanks to Tristram McPherson, Ben Lennertz, Robin McKenna, Jussi Suikkanen, Caj Strandberg, Ragnar Francén Olinder, John Eriksson and Christian Munthe for extensive comments on earlier versions, and to two anonymous referees. Work on this paper has been supported by the Swedish Research Council, grants 2009-1507 and 2012-988.

2 For discussion, see Björnsson (2013).

${ }^{3}$ For arguments of this form, see e.g. Brink (1989, ch. 2); Huemer (2005, chs. 2-3); Lyons (1976, 1920); McNaughton (1988, 39-41); Sayre-McCord (2006, 42); Shafer-Landau (2003, chs. 2-3); Smith (1994); Streiffer (2003, ch. 1). 
reject the second premise, either denying that absolutism can make good sense of the unity of moral discourse, or, as is more common, arguing that non-absolutist accounts can. My concern here is to develop the latter sort of objection, an objection typically associated with quasi-realist defenses of non-cognitivism, ${ }^{4}$ but lately pursued more generally. ${ }^{5}$ Instead of focusing directly on the moral domain, I first look at how some aspects of unity can be found in paradigmatically non-absolutist domains, involving judgments of personal taste and likelihood. I then proceed to provide independently motivated accounts of attributions of agreement, disagreement, correctness and incorrectness that can explain both why absolutist domains display all aspects of unity and why certain non-absolutist domains display some. Against this backdrop, I provide preliminary reasons to think that the unity of moral discourse, to the extent that moral discourse displays unity, can be given a non-absolutist explanation.

\section{Metaethical absolutism}

As I have indicated, a central part of my strategy in the following sections is to draw lessons from attributions of disagreement and correctness in the domains of personal taste and likelihood. Unfortunately, the semantics for concepts and predicates of taste and likelihood is notoriously contested. To allow us to distill the lessons without getting entangled in these debates, this first section introduces a way of understanding absolutism that stays clear of controversial talk about truth, content, or propositions expressed.

As I will understand it here, absolutism is a claim about moral judgments and moral concepts, not about moral language. (Here and in what follows, I use "judgment" to denote either the psychological act of judging whether something is such-and-such, or the psychological state resulting from that act; I will use "claim" to denote the declarative expression of a judgment.) More generally, what I will call "ABSOLUTISM" about a concept is the claim that the concept has non-relative satisfaction conditions that are constant across judges and judgments. The "satisfaction conditions" of a concept expressed by some predicate $\mathrm{F}$ are those conditions that an item X needs to satisfy in order for someone's act of judging that $\mathrm{X}$ is $\mathrm{F}$ to be internally successful. Finally, for an act of judging whether $\mathrm{X}$ is $\mathrm{F}$ to be "internally successful" is for it to achieve what one is aiming at - what one tries to get right - merely in virtue of judging whether $\mathrm{X}$ is $\mathrm{F} .{ }^{6}$ (Notice that internal success conditions are properties of

\footnotetext{
${ }^{4}$ See e.g. Björnsson and McPherson (2014); Blackburn (1984); (1991b); (1993a); Gibbard (2003); Hare (1970); Stevenson (1944); Tersman (2006).

${ }^{5}$ See e.g. Björnsson and Finlay (2010); Finlay (2014, ch. 8); Plunkett and Sundell (2013).

${ }^{6}$ In judging whether X is $\mathrm{F}$ (whether Belgium has a king, say), I might of course have a variety of goals other than getting the judgment right (to test my memory, to save face, etc.), but those are not goals I have merely in virtue of making the judgment.
} 
judgments, not of assertions.) To say that ABSOLUTISM holds for F, then, is to say that any two judges who are judging in good faith whether some $\mathrm{X}$ is $\mathrm{F}$ are trying to get the same things right, or, equivalently, that their judgments have the same (non-relative) internal success conditions. If one of them judges that $\mathrm{X}$ is $\mathrm{F}$ and the other that $\mathrm{X}$ is not $\mathrm{F}$, then if one is successful, the other is not; if both make the same judgment, then they are equally (un)successful. ${ }^{7}$

Admittedly, talk about what judges are "trying to get right" when judging whether $\mathrm{X}$ is $\mathrm{F}$ or about the "internal success conditions" of their judgments might seem to be nothing but a roundabout way of talking about the truth-conditions of judgments whether something is $\mathrm{F}$. That is not quite right, however, and it will be important later that the two come apart on occasion. There are cases in which we have reasonably clear ideas about what judges are trying to get right, and whether they are trying to get the same thing right, well before we decide between quite different accounts of the semantics of the concept in question. There are also cases where we can agree that someone's judgment has been internally successful but where it seems inappropriate for us to say that their judgment was true.

For illustration, consider an example involving judgments of personal taste. Gus and Tibus both want something to enjoy on their way home from work. Each is looking at the vending machine, trying to determine whether there is something tasty on offer. In doing so, each is trying to get something right, but if they have different palates, they are presumably trying to get different things right. Each, it seems reasonable to say, is trying to determine whether there is anything on offer that satisfies his palate (perhaps under suitably normal conditions). (Each, like most of us, knows perfectly well that others have other gustatory preferences, but neither would think that this is relevant for the judgment he is making.) Because of this, it might be that if Gus and Tibus both conclude that there is something tasty in the vending machine, only one of them would be successful in his endeavor. ${ }^{8}$ Given this, we know enough to conclude that ABSOLUTISM doesn't hold for the kind of tastiness concept exemplified by Gus' and Tibus' judgments. ${ }^{9}$ However, we are far from determining the

\footnotetext{
${ }^{7}$ Here and throughout I set to the side putative counterexamples to the law of non-contradiction.

${ }^{8}$ It should be noted that judgments of taste sometimes have more interpersonal or idealizing pretentions, being concerned with whether something accords with the taste of most people, or with suitably refined palates (cf. Doerfler (2012); Egan (2010); Loeb (2003)). This, however, does not mean that all judgments of taste have such interpersonal or idealizing ambitions (cf. Goodwin and Darley (2008)). In fact, I believe that the most common kind of attribution of tastiness in particular lacks these ambitions, and this is the kind that concerns us here.

${ }^{9}$ By contrast, ABSOLUTISM might well hold for explicitly relativized tastiness judgments: if Gus and Tibus were both judging whether the machine contains something tasty for Gus, they would likely be trying to get the same thing right. In saying this, I distinguish the concept at play when Gus and Tibus
} 
semantics of tastiness claims, i.e., of declarative expressions of tastiness judgments. Perhaps such claims are best analyzed along contextualist lines: a tastiness claim asserts the proposition that some relevant subject(s) - typically the speaker - is disposed to have positive gustatory experiences from the item in question. ${ }^{10}$ Or perhaps an expressivist analysis is preferable: tastiness claims express but do not ascribe such a disposition. ${ }^{11}$ Or perhaps the proposition asserted or its truth-value depends on the dispositions of those who assess the claim semantically, not on those of the speaker. ${ }^{12}$ By focusing on what judges are trying to get right in making their judgments instead of on the semantics of characteristic expressions of such judgments, we can avoid getting involved in differences between such analyses until they become relevant for our purposes.

The case of tastiness judgments also illustrates the possibility of attributing internal success to judgments without thinking that they are true. Suppose that after looking at a particular item in the vending machine, Gus exclaims, "ah, there's something tasty!" If the item in question is one that we find disgusting, we will be reluctant to say that Gus was right, or that he had said something true. But his judgment would clearly have been internally successful if the machine contained something that would satisfy his palate.

ABSOLUTISM, then, is not understood in terms of truth, or propositions expressed, but in terms of the satisfaction conditions of concepts, which in turn are understood in terms of the judgment-internal success of the relevant kinds of judgments, and the concepts involved. Metaethical absolutism is ABSOLUTISM about moral judgments and concepts. More specifically, I will take it to be ABSOLUTISM about concepts that are central to moral thinking and involved in paradigmatic cases of moral disagreement: concepts of intrinsic good, moral wrongness and blameworthiness, justice, normative reasons, and ought-all-things-considered-to-be-doneness, to mention some of the most prominent. ${ }^{13}$

are judging whether the machine contains something tasty from the concept at play when they are judging whether it contains something that is tasty for Gus. I think of a concept expressed by a predicate F as a kind of mechanism the operation of which constitutes the agent's activity of judging whether something is F. Since the two italicized characterizations of judgments in the previous sentence pick out two extensionally different kinds of judgments, they also pick out two different kinds of concepts. This is not to deny that the concepts are closely related - for all I have said, they might be simultaneously at play when Gus is judging whether something is tasty. I thank Ben Lennertz and an anonymous referee for pressing me on this point.

${ }^{10}$ See e.g Glanzberg (2007); Schaffer (2011); Sundell (2011).

${ }^{11}$ See Buekens (2011), who combines contextualist and expressivist elements.

12 See e.g. Egan (2010); Lasersohn (2005); Pearson (2013); Stephenson (2007).

${ }^{13}$ Just as non-ABSOLUTISM about tastiness is compatible with a variety of analyses of "tasty", metaethical absolutism, as it is understood here, is itself compatible with different semantic views: 


\section{The argument from UNITY}

Hardly anyone defends absolutism with reference to detailed studies of the individual parties of moral disagreements and what each party is trying to get right when making their judgment. Rather, belief in absolutism is grounded in general and easily accessible aspects of moral judgment and moral discourse. The most important and pervasive source of support for absolutism is a package of interrelated features that people normally seem to attribute to paradigmatically absolutist discourse and thinking, but not to clear cases of non-absolutist discourse. The package can be described in slightly different ways, but I take the set of features that I will call DISAGREEMENT, CORRECTNESS, INDEPENDENCE, and NO RELATIVIZATION to cover its core. I will refer to this set as "UNITY", as it is meant to represent how we take people to be concerned with the same issue in paradigmatically absolutist discourse.

DiSAGREEMENT: If $\mathrm{A}$ claims that $\mathrm{X}$ is $\mathrm{F}$ and $\mathrm{B}$ that $\mathrm{X}$ is not $\mathrm{F}$, then in agreeing with one claim, one disagrees with the other. ${ }^{14}$ (When $\mathrm{A}$ and $\mathrm{B}$ both agree with their own claims, they disagree with that of the other.)

CORRECTNESS: If A claims that $\mathrm{X}$ is $\mathrm{F}$ and $\mathrm{B}$ that $\mathrm{X}$ is not $\mathrm{F}$, then if one claim is correct (true, right) the other must be incorrect (false, wrong). ${ }^{15}$

INDEPENDENCE: What determines the correctness of A's claim that $\mathrm{X}$ is (not) $\mathrm{F}$ are features of $\mathrm{X}$ that do not essentially depend on A's attitudes toward X. ${ }^{16}$

Kantian prescriptivism, non-naturalistic as well as naturalistic realism, what Sharon Street (2006) calls "rigidifying antirealism", and ideal observer or advisor theories. It is incompatible with various forms of relativism as well as with at least some versions of non-cognitivism. For example, Gibbard's (2003) view seems perfectly compatible with the assumption that when different people are deciding whether to plan to $\varphi$ in $\mathrm{C}$ (i.e. judging whether $\varphi$-ing is the thing to do in $\mathrm{C}$ ), what standards for such planning they are ultimately trying to conform to might be quite different. However, absolutism is compatible with a contextual semantics for evaluative and normative expressions such as "good" and "ought". Even if such terms pick out different ends or norms in different contexts, it might be that they pick out the same ends or norms when used in moral contexts: moral value and the moral law, say. Finally, as it stands, the definition allows for error-theoretic versions of absolutism, according to which no positive moral judgments are ever internally successful.

14 Again, I set to the side complications due to obvious cases of vagueness and putative counterexamples to the law of non-contradiction.

${ }^{15}$ Cf. n. 14.

${ }^{16}$ For simplicity, I'll ignore cases where $\mathrm{X}$ itself involves A. The blocking of essential dependence allows that contingent effects of A's thinking might affect X's F-ness. (For example, that A thinks that it would 
NO RELATIVIZATION: If one is involved in disagreement about whether $\mathrm{X}$ is $\mathrm{F}$, one does not take answers of the form $X$ is $F$ relative to $Y$ and $X$ is not $F$ relative to $Z$ to resolve the disagreement (unless a non-relative answer can be derived from these).

Talk about "agreement" and "disagreement" can be understood in different ways, some of which will involve the other features of UNITY, in particular CORRECTNESS. However, I think that there are weaker notions, captured by most everyday attributions of agreement and disagreement. The notions I have in mind here can be roughly operationalized as follows: B agrees (disagrees) with A's claim that such-and-such if and only if B's judgment about the matter would make it natural to say "A said that such-and-such, and B thinks so too (but B doesn't think so)". They are also naturally expressed using "yes" and "no" in reaction to claims, where the target of the acceptance or rejection is not intuitively metalinguistic, concerned with the pronunciation or choice of words as in: (1) A: "Pedants correct the [pro-noun-ciation] of others. B: "No they don't. They correct the [pro-nun-ciation] of others." (2) A: "Burgers come with chips." B: "No they don't. Burgers come with french fries." 17

It might seem plausible that, if we let "F" express any of the moral concepts with which absolutism is concerned, UNITY represents how engaged participants tend to understand moral reasoning and moral debate, even in cases of deep moral disagreement. (Think for example of disagreements about whether we have an obligation to help distant strangers people in need when we can do so at little cost to ourselves.) By contrast, we do not understand recognizably non-ABSOLUTIST domains as involving all features of UNITY. For example, suppose A claims that the cathedral is to the left while B denies that it is to the left, but that $\mathrm{A}$ and $\mathrm{B}$ express directional judgments made from different spatial perspectives. ${ }^{18}$ Then we can well agree with and deem true or correct (or disagree with and deem wrong, false or incorrect) what both said. Furthermore, this would be true even if A and B were allknowing and perfectly rational creatures, and any disagreement about whether the cathedral is to the left might be fully resolved by determining whether it is to the left relative to a certain perspective.

be morally wrong to treat $\mathrm{B}$ in a certain way might make it wrong to treat $\mathrm{B}$ in that way under certain circumstances.)

17 The notion is thus somewhat narrower than that employed by Sundell (2011, 275-76), from which I borrow the two examples.

${ }^{18}$ In this case, ABSOLUTISM fails for A's and B's judging whether the cathedral is to the left when we individuate kinds of judgments and corresponding concepts in a way that ignores differences in perspective. ABSOLUTISM might well hold for judgments whether the cathedral is to the left from A's perspective. Cf. $n 9$. 
Insofar as it satisfies UNITY, then, moral discourse and thinking very much looks like an absolutist domain, and looks unlike the clearest cases of non-absolutist domains. Moreover, if the moral domain behaves in ways characteristic of absolutist domains, it might seem reasonable to assume that it is an absolutist domain, unless we have positive reasons to the contrary. (If it quacks, walks, and looks like an absolutist domain, our default assumption should be that it is one.)

This argument can be strengthened by the following consideration: UNITY not only seems to represent an ordinary understanding of absolutist discourse, but an understanding that would seem perfectly adequate given absolutism. If we are indeed concerned to get the same things right, it makes sense to let agreement, disagreement, and assessments of correctness follow these patterns. If we are not concerned to get the same thing right, the rationale for these features of the practice seems much less clear.

Metaethical absolutism might seem to be jointly supported, then, by its promise to make straightforward sense of UNITY and by the fact that we characteristically recognize its full package in paradigmatically absolutist domains of discourse and judgment, but never in paradigmatically non-absolutist domains. Conversely, forms of non-absolutism seem to be undermined. Or so people have thought. ${ }^{19}$

There are of course various ways in which one might resist the argument from UNITY. One is to deny that moral discourse and thinking display UNITY. Empirical evidence suggests that not everyone always understands moral discourse to satisfy all aspects of UNITY. However, patterns of understanding characteristic of paradigmatically absolute domains seem predominant (especially within cultures) for what most people take to be serious and uncontroversially moral wrongdoing, and considerably stronger than for what is commonly understood as matters of taste..$^{20}$ Moreover, various rejections of aspects of UNITY do not immediately undermine the argument, as at least some such rejections can be understood as expressing doubts about the feasibility of insisting upon or producing generally convincing arguments for the moral views in question, or as expressions of degrees of tolerance; ${ }^{21}$ further empirical research is needed.

My focus here will instead be on the claim that absolutism provides the best explanation of UNITY, to the extent that UNITY is indeed displayed in the moral domain. Elsewhere I have elaborated on the familiar relativist or non-cognitivist argument that widespread and seemingly fundamental moral disagreement undermines straightforward absolutist

\footnotetext{
19 For references, see n. 2.

20 See e.g. Goodwin and Darley (2008); J. C. Wright et al. (2012); Sarkissian et al. (2011).

21 See J. C. Wright et al. (in press).
} 
explanations of UNITY. ${ }^{22}$ My specific objective here is to propose what I take to be the most promising route for non-absolutist explanations.

Non-absolutist accounts of UNITY can often seem problematic, relying on strong forms of motivational internalism, or failing to make sense of disagreement that involves no clash of attitudes. ${ }^{23}$ Moreover, one might worry that such accounts are too disconnected from a general understanding of why UNITY is displayed elsewhere, and inevitably ad hoc in their appeal to mechanisms that are clearly not at work in paradigmatic absolutist domains. ${ }^{24}$ In the absence of other strong reasons to reject absolutism, then, one might well feel that UNITY gives it considerable support.

What I will argue in this paper, however, is that non-absolutist explanations of UNITY need not be ad hoc. Aspects of UNITY seem to hold not only in paradigmatically ABSOLUTE domains, but also, to a limited extent, in paradigmatic non-ABSOLUTE domains, such as those of personal taste and epistemic modals. Moreover, given an independently plausible general account of the mechanisms governing attributions of agreement or disagreement and attributions of correctness or incorrectness in both ABSOLUTE and non-ABSOLUTE domains, such mechanisms might well give rise to the full range of UNITY independently of whether ABSOLUTISM holds for that domain. This leaves open the possibility of an independently motivated and entirely non-ad hoc non-ABSOLUTIST account of unity in the moral domain, and one that does not rely on strong forms of motivational internalism.

\section{Aspects of UNITY in non-absolutist discourse: the case of tasty and likely}

We have already noted that elements of UNITY are violated by claims about whether something is to the left, and the same is true about claims employing a variety of contextdependent locutions, including "local", "ready", and "tall". But judgments expressed by other paradigmatically non-ABSOLUTIST locutions - in particular epistemic modals and various

\footnotetext{
22 See Björnsson (2012).

${ }^{23}$ Most metaethicists these days reject strong motivational internalism (see Björklund et al. (2012)). For discussion of problems with accounts of disagreement in terms of clashing attitudes of the sort proposed by Stevenson's (1944); (1963), see e.g. Gibbard (2003), ch. 4; Dreier (2009), and Ridge (2013). ${ }^{24}$ Simon Blackburn (1991a); (1991b), in a debate with Nicholas Sturgeon (1991), argues that the best "projectivist" account of sameness of meaning is the mere application of a more general account, covering ordinary descriptive discourse. Michael Ridge (2013) puts forth an account of disagreement that is meant to be general and avoid problems with Stevenson's and Gibbard's proposals. (I think that though Ridge's account is on the right track, but argue elsewhere that it runs into problems with disagreements about taste, and fails to capture what is ultimately driving intuitions about disagreement (cf. Björnsson (ms)).) The account of UNITY developed here could be seen as an effort to lay the ground for a more complete and independently compelling picture in the spirit of these earlier proposals.
} 
predicates of personal taste - seem to satisfy several aspects of UNITY even on occasions where judges are trying to get different things right. Understanding why these judgments display such patterns will tell us what to expect in the case of moral judgments.

In this section, we will consider one example each of two classes of predicates: predicates of personal taste, and epistemic modals. Throughout, I will appeal to phenomena that have been adduced in support of assessor-relativism in these areas, but as before I will remain neutral as to whether relativistic analyses of these phenomena are preferable to contextualist or expressivist analyses.

\section{Tastiness}

Start with predicates of personal taste, exemplified by tasty. Suppose that our friends Gus and Tibus have each decided to determine whether Marmite is as tasty as some say, or as vile as others claim. Each has a taste, and each expresses his judgment, in soliloquy:

Gus: "That's surprising. Marmite's tasty."

Tibus: "What a disappointment. Marmite's not at all tasty."

We have already said that ABSOLUTISM is violated for tastiness judgments. When Gus judges that Marmite is tasty, he doesn't take the reactions and judgments of others to matter for his verdict: the ultimate arbiter is whether Marmite would give him a pleasant gustatory experience (perhaps under normal circumstances). Likewise, mutatis mutandis, for Tibus. ${ }^{25}$ Nevertheless, it seems that Gus and Tibus disagree, and more generally that if someone agrees with one of the two tastiness claims, he thereby disagrees with the other. So DISAGREEMENT seems to be satisfied for tastiness claims, even when judges are concerned to get different things right when making the judgments expressed. ${ }^{26}$ Relatedly, it seems a little problematic to think that both Gus' and Tibus' claims are true, as that might seem to involve agreeing with both their claims. On the other hand, many would be hesitant to think that Gus's (or Tibus's) claim was incorrect or false merely on account of disagreeing with him about the tastiness of Marmite. So CORRECTnEss has at most a limited appeal. Similarly, InDEPEndence is problematic. Many of us would find it misplaced of Tibus to deem Gus's claim incorrect or false without taking into account Gus's taste disposition. Likewise, finally, for NO RELATIVIZATION: once we have determined for whom Marmite is and is not tasty (and under what circumstances), there seems to be nothing left of the question of whether it is tasty. ${ }^{27}$

\footnotetext{
${ }^{25}$ Assuming, as before, that we are concerned with expressions of personal taste (cf. n 8).

${ }^{26}$ This is of course part of what has motivated various relativist theories about taste judgments (see e.g. Egan (2010); Kölbel (2004); Lasersohn (2005); Pearson (2012); Stephenson (2007)).

27 In effect, Robin McKenna (2014) relies on this mismatch between DISAGREEMENT and CORRECTNESS in the case of taste judgments to raise a problem for my earlier treatment of
} 
Notice, though, that attributions of correctness and incorrectness seem unproblematic when all involved are assumed to have similar taste reactions to the item in question. If Gus and Tibus knew that they have the same taste and Tibus claimed that Marmite isn't tasty while misremembering the taste of Marmite, Gus could naturally say, "you're wrong, it really is quite tasty", and if Tibus had claimed that Marmite is tasty, Gus could have naturally replied "that's true, it really is". In such contexts, tastiness judgments might seem to satisfy CORRECTNESS.

Although the example of tastiness discourse shows that DISAGREEMENT is not unique to ABSOLUTIST domains, it fails to satisfy the other aspects of UNITY, except to a limited extent within contexts where an overlap of taste dispositions is assumed. In itself, then, the case of tastiness might seem to strengthen the argument from UNITY: we (or at least many of those involved in engaged moral disagreement) understand moral discourse along the lines of absolutist discourse, not along the lines of this clearly non-absolutist domain.

\section{Likelihood}

Another family of non-absolutist predicates displaying aspects of UNITY are epistemic modals, expressed in English by locutions such as "likely", "improbable", "might", "possible", "can", and "must". Here we will focus on likelihood judgments. Suppose that Basil needs to get hold of his cat Felix to bring him to the veterinarian. Basil muses:

"Felix does sometimes wander off to the stream to fish, but his favorite pastime is chasing birds, and most birds are at the apple orchard today. So he is likely to be in the orchard."

What Basil tried to get right in drawing his conclusion was a relation between evidence available to him before the beginning of his search and the various places where Felix might be: his question concerns where Felix is likely to be given that evidence. He knows that someone might have better evidence - quite a few people are out and about and might have seen Felix - but this doesn't affect what he is trying to get right, as he has no feasible way of accessing that evidence. ${ }^{28}$ As it happens, Claudia is one of the people who had seen Felix, as he was heading in the opposite direction of the apple orchard a few minutes ago, towards the stream where she knows that he occasionally goes to fish. When Claudia asks herself where Felix might be, she concludes:

disagreement in Björnsson and Finlay (2010). The account of attributions of disagreement and attributions of correctness and incorrectness (truth and falsehood) provided in sections 4 and 5 promises a principled explanation of this mismatch.

${ }^{28}$ In describing this scenario, I am not denying that we sometimes make likelihood judgments with more interpersonal or objective pretensions, just that this is what is going on here. Cf. n. 27. 
"Felix is unlikely to be in the apple orchard."

Like Basil, Claudia knows that someone might have better evidence regarding Felix's whereabouts but lacks any feasible way of getting access to that evidence. Her judgmental efforts, it seems, are internally successful if Felix is unlikely to be in the orchard given evidence available to her. Since the evidence available to Basil and Claudia differs, ABSOLUTISM doesn't hold for their likelihood judgments.

At the same time, it seems that DISAGREEMENT is satisfied: intuitively, if we were to agree with or accept Basil's claim that Felix is likely to be in the orchard, we would disagree with and have to reject Claudia's claim that he is unlikely to be in the orchard. Moreover, CORRECTNESS might seem to be satisfied in at least some contexts where ABSOLUTISM is violated. Consider the following exchange:

\section{FINDING FELIX}

Alicia: "I need to find Felix. I wonder where he might be."

Basil: "The birds are in the orchard today. He is likely to be there."

Claudia: "I think that's wrong, Alicia. I saw Felix head in the other direction earlier. He is more likely to be by the stream."

Claudia's assessment of Basil's initial claim seems natural enough. Claudia thinks that Felix is unlikely to be in the orchard, and this seems to not only force her to reject Basil's claim, but also to negatively assess its correctness. Moreover, CORREGTNEss does not seem to presuppose ABSOLUTISM: it seems natural to assume that Claudia's assessment was based on evidence that Basil was not concerned to relate to when making his judgment, evidence available only to her. ${ }^{29}$

Similarly, I would expect parties of FINDING FELIX to take the other aspects of UNITY to be satisfied. INDEPENDENCE will seem to be satisfied, as Claudia's and Alicia's assessments of the correctness of Basil's judgment will take into account any available evidence concerning

\footnotetext{
${ }^{29}$ It might be argued that this assumption should be abandoned, and that the best explanation of why CORRECTNESS seems to hold in this context is that we take Basil to express a "communal" judgment, concerned with what is likely given the information available to either of the parties of the conversation. If he were, then ABSOLUTISM would hold for Basil and Claudia's judgments. The analogous argument has been made by Janice Dowell (2011) for the case of epistemic "might". I defend the naturalness and correctness of the solipsistic interpretation against Dowell's argument at some length in Björnsson and Almér (2010); Montminy (2012) independently replies along partly similar lines (also cf. Swanson (2011)).
} 
Felix's whereabouts, without restriction to what information Basil had. Likewise for NO RELATIVIZATION: If Basil and Claudia agreed that Felix is likely to be in the orchard given Basil's evidence and unlikely to be there given Claudia's, they would not thereby have agreed about whether Felix is likely to be in the orchard or not.

It seems, then, that at least from the point of view of participants, some cases of nonabsolutist discourse can display all four aspects of UNITY. But the picture is complicated, as not all the aspects hold universally, or from all points of view. Consider:

\section{HINDSIGHT:}

Having talked to Basil, Claudia and some kids, you now know the following: (1) At nine o'clock this morning, Basil concluded, based on long experience and knowledge about the whereabouts of the birds, that Felix was likely to be in the orchard. (2) Independently, and at about the same time, Claudia concluded that Felix was unlikely to be in the orchard, as she had seen him take off in the opposite direction, towards the stream, earlier that morning. (3) As a matter of fact, however, and surprisingly given either Basil's or Claudia's evidence, Felix was in the back yard at the time, playing with the neighborhood kids. ${ }^{30}$

What is interesting about our situation in HINDSIGHT is this: while we know where Felix actually was, and what evidence different people had about his whereabouts, we do not seem to be in a position to judge whether Felix was likely to be in the orchard. It might be natural to say that Felix was unlikely to be in the orchard in light of Claudia's information, but likely to be there in light of Basil's, but it would seem odd for us to judge, based on everything we know, without explicit relativization to some other epistemic perspective, that Felix was unlikely to be in the orchard.

Now consider the four aspects of UNITY, as they will appear from our HINDSIGHT perspective. First, DisAGREEMENT might seem difficult to assess. Exactly because we cannot judge (without relativization) whether Felix was likely to be in the orchard, it is unclear whether we are in a position to agree or disagree with Basil or Claudia's judgments. Perhaps, though, it is still true that if one were to agree with Basil's judgment that Felix was likely to be in the orchard - if one were to judge that Felix was likely to be in the orchard - one would have to reject Claudia's judgment, and vice versa. CORRECTNESS and INDEPENDENCE seem more deeply problematic, however, as natural assessments of the correctness of Basil's and

\footnotetext{
${ }^{30}$ von Fintel and Gillies (2008) appeal to retrospective cases like this to undermine evidence for assessor-relativism of the sort defended by Egan (2007), MacFarlane (2011) and Stephenson (2007). Some of the other cases they appeal to transpose to the case of "likely".
} 
Claudia's judgments seem to relate them to their respective epistemic perspectives at the time, rather than to information had by us now, or by others at the time of Basil's and Claudia's judgments. For example, the following assessment of Basil's judgment, explicitly relating to his information, seems natural enough from the perspective of HINDSIGHT:

"Basil thought that Felix was likely to be in the orchard. That was correct: given information available to him at the time, Felix was indeed likely to be in the orchard."

By contrast, this assessment, relying on information not available to Basil, does not:

"Basil thought that Felix was likely to be in the orchard. That was incorrect: as we now know from the kids, Felix was not at all likely to be in the orchard. "\$1

Finally, NO RELATIVIZATION seems to be violated from the HINDSIGHT perspective. If we have answered questions of the sort "from epistemic perspective E, where was Felix most likely to be?" for all interesting perspectives, we seem to have exhaustively resolved any disagreements we might have had about where Felix was likely to be.

In this section we have seen how two paradigmatically non-ABSOLUTIST domains satisfy some, but not all, aspects of UNITY, and sometimes only partially. In itself, this might seem to reinforce the argument from UNITY. What I will argue in the next three sections, however, is that when we understand why aspects of UNITY are displayed in ABSOLUTIST discourse and partially displayed in non-ABSOLUTIST discourse, there is room for a non-ABSOLUTIST account of UNITY in the moral domain.

\section{Understanding DISAGREEMENT}

The purpose of this and the following section is to propose, in outline, general accounts of the various phenomena involved in UNITY. In particular, I will sketch accounts of what it is to agree or disagree with what someone says or thinks, and accounts of what it is to take a claim or judgment to be correct or true, or incorrect or false. The guiding principle is that the

\footnotetext{
${ }^{31}$ In eliciting intuitions about cases like these, it is important to be aware of various sources of error. One is that attributions of correctness might target the formation of a judgment rather than the judgment formed. Another is that people might take beliefs that happen to be false to be less justified (Young et al. (2010)), which can lead them to think that the judge (Basil, say) had not adequately taken into account available information. Yet another is that people who know whether $p$ is the case will fail to assess the claim that $p$ is likely, instead assessing the claim that $p$, as this is an epistemically more relevant target of assessment (cf. Almér and Björnsson (2009); Björnsson and Almér (2010)). Still, new evidence strongly suggests that hindsight judgments follow the patterns postulated here (Knobe and Yalcin (forthcoming)).
} 
accounts should not only predict, but also make intelligible why all features of UNITY are present in the case of paradigmatically absolutist discourse, none are in certain kinds of nonabsolutist discourse, and some are, to various degrees, in the case of tastiness and likelihood judgments.

In this section, I propose a general account of agreement and disagreement. As illustrated by cases involving tastiness and likelihood judgments, agreeing with someone's claim is not essentially a matter of thinking that they have been internally successful in making the judgments they expressed. The explanation for this, I will argue, is that agreement and disagreement relate to the claim's communicative function, and to the related phenomena of accepting or rejecting the claim.

Generally, accepting or rejecting an utterance is a matter of going along with, or ruling out going along with, the standard flow of communication initiated by the utterance. We have ways of saying, asking, entreating, and so forth, because such acts tend to have specific communicative effects: that our audience believes what is said, takes on the task of answering the question, forms intentions to comply, and so forth. To some extent, our understanding of communicative function might be closely tied to an independent understanding of speakers' perlocutionary intentions. But it is primarily driven by our general understanding of the words employed and syntax, including the sentence form (declarative, interrogative, imperative), and aspects of the context implicated by this understanding. Plausibly, this general understanding is an understanding of the conventional communicative function of the sorts of expressions involved, adapted to the characteristic psychological effects on hearers of the expressions that explains why, in general, we tend to use those kinds of expression, and under what circumstances. ${ }^{32}$ Even when speakers clearly do not intend us to believe a claim, answer a question, or fulfill a request, then, we can readily understand their utterances as utterances whose communicative function, in virtue of the conventional function of its various elements and the context, is to elicit judgments or intentions in hearers.

The idea now is that to accept a claim, question, or request, is exactly to do one's part as a hearer in the performance of its communicative function: judging that something is the case, intending to provide an answer, or intending to comply. Correspondingly, to reject an

\footnotetext{
${ }^{32}$ See e.g. Millikan (1984); Stevenson (1944). Following Millikan (1998), I take speech acts to be usefully categorized based on their conventional communicative function, and traditional speech act categories to closely track such functions.

Notice that the conventional communicative function of an utterance can be relational and context-dependent. For example, it is presumably a conventional function of an utterance in the declarative ("The cathedral is to the right") to produce or make occurrent a judgment the content of which depends on the words constituting the sentence as well as context needed to fix the content of context-dependent expressions.
} 
utterance is to be in the sort of state that most directly rules out being in the former state: judging that something is not the case, intending not to provide an answer, intending not to comply. ${ }^{33}$ Our primary concern here is specifically with what I have called "claims"expressions of judgment in the declarative. The characteristic communicative function of claims, I take it, is to produce or make occurrent judgments in hearers: we characteristically make claims because they produce or make occurrent suitably related judgments in hearers, and our understanding of sentences in the declarative is shaped by this function. ${ }^{34}$ I thus propose that:

ACCEPT/REJECT: To accept a claim is to make the judgment that would constitute doing one's part as a hearer in fulfilling the characteristic communicative function of that sort of claim; to reject the claim is to make the contrary judgment. ${ }^{35}$

${ }^{33}$ The notion of communicative function is closely related to the notion of an expression's context change potential in dynamic semantics, and to the resultant of the force and content of a speech act (see e.g. Stalnaker (1999)). Likewise, the notion of acceptance of a claim employed to be introduced is closely related to notion of acceptance employed by Stalnaker (see e.g. (2002)). However, the use to which it is put here does not presuppose the adoption of that semantic framework: for all I say here, the meaning of sentences might be analyzed in some other way.

${ }^{34}$ Relatedly, Millikan's (1984) argues that the "stabilizing proper function" of the indicative mood is to produce true belief in hearers: true belief because this is what both speakers and hearers tend to have an interest in such that this reinforces speaker and hearer dispositions. This explanation is correct and important, but for the explanations of acceptance, rejection, agreement and disagreement developed here, we can bracket the truth-value of the judgment.

${ }^{35} \mathrm{I}$ am assuming here that the judgment that not-P and the judgment that $\mathrm{P}$ are each other's contraries. (Dialetheists will need a somewhat different account than that offered here; I set that complication to the side.)

One might of course resist accepting an utterance without thereby rejecting it, namely by withholding judgment or more generally being undecided. The sort of rejection in judgment that we are concerned with here also contrasts with a metaconceptual or metalinguistic refusal to employ a certain term or concept (because of its despicable connotations, say). I thank Guy Fletcher for raising this complication. Another complication, raised by Michael Ridge, comes from contents that are in certain ways peripheral to a clam, such as the implications of "even" in "Even Granny had some wine", or parentheticals like that in "Lance Armstrong, who was born in Copenhagen, won the Tour the France seven times". To produce or make occurrent acceptance in judgment of these contents seem to be part of the communicative function of the claims, but contrary to ACCEPT/REJECT one might think it possible to reject these contents without rejecting the claims. I lack space here for a full discussion, but I am inclined to deny that possibility: we do reject a claim if we reject some of its peripheral contents. The reason one might nevertheless feel that one "accepts the claim" is simply that these contents are less central to communicative concerns: one can accept the central parts. 
The basic disagreement phenomenon is then understood as involving two claims the acceptance of one rules out the acceptance of the other; disagreements involving judgments are understood as propensities for disagreements of this basic form:

\begin{abstract}
AGREE/DISAGREE: Two claims are in agreement when accepting (rejecting) one would mean accepting (rejecting) the other; they are in disagreement when accepting one would mean rejecting the other. To agree (disagree) with some claim $\mathrm{C}$ is to make a judgment the characteristic declarative expression of which would be in agreement (disagreement) with $\mathrm{C}$. To agree (disagree) with some judgment $\mathrm{J}$ is to make a judgment the characteristic declarative expression of which would be in agreement (disagreement) with the characteristic declarative expression of $\mathrm{J} .{ }^{36}$
\end{abstract}

Consider how this applies to the case of most ordinary, non-relative, descriptive claims. The characteristic communicative function of such claims, we can assume, is to inform (or remind) hearers about a certain aspect of objective reality. Here, the judgment that satisfies the characteristic communicative function of the claim is simply the judgment that this aspect obtains. To accept the claim is thus to make such a judgment, and to reject the claim is to make the contrary judgment. Given this, AGREE/DISAGREE yields DISAGREEMENT for discourse involving ordinary, non-relative, descriptive claims. If A said that X is F and B said $\mathrm{X}$ is not $\mathrm{F}$, and $\mathrm{F}$ is a non-relative descriptive predicate, then accepting one claim means rejecting the other. ${ }^{37}$ Correspondingly, agreeing with A's (B's) claim means making the judgment characteristically expressed by saying that $\mathrm{X}$ is (not) F, and thus to disagree with B's (A's).

If this account of DISAGREEMENT in paradigmatically ABSOLUTIST discourse is correct, the reason that claims expressing tastiness and likelihood judgments follow the pattern of DISAGREEMENT should be that their communicative functions are relevantly similar to those of ordinary descriptive statements. So what are those communicative functions?

Start with tastiness claims. Their characteristic function, I suggest, is to create (or make occurrent) tastiness beliefs in hearers and corresponding expectations of what hearers will find tasty or not, thus providing gustatory guidance. ${ }^{38}$ It is clear that we routinely do form tastiness

\footnotetext{
${ }^{36}$ Understanding disagreement in judgment in terms of disagreement between claims might seem roundabout, but I argue elsewhere that this idea explains why agreement and acceptance can come apart in the case of tastiness judgments (Björnsson (ms)).

${ }^{37}$ Ignoring, as before, complications related to vagueness and dialetheism.

${ }^{38}$ More generally, tastiness claims function to express the speaker's taste judgments, which can be done to guide taste expectations, but at other times merely to convey one's food preferences (as when small children express their taste judgments to parents), or perhaps to compliment the chef. However, as I have argued elsewhere (Björnsson and Almér (2010), pp. 23-6), this general expressive function
} 
beliefs on the basis of tastiness claims, and clear that speakers adjust their utterances in light of this effect, making explicitly subjective claims (" $I$ think that this is really tasty") when they have specific reasons to suspect that the audience does not share their taste preferences and will be mislead if accepting a bare tastiness claim. ${ }^{39}$ Moreover, it makes good sense that expressions of tastiness judgments would have this function. True, differences in taste are common enough for us to only sometimes be in a position to confidently judge that all our hearers will share our taste reaction to a particular item. But there is enough overlap for expressions of subjective judgments to serve as reasonably reliable guides for others who have not yet tasted the item. ${ }^{40}$

Given this communicative function of tastiness claims, the response required for its fulfillment is that hearers expect to have the corresponding taste experience from the item in question. Given AGCEPT/REJECT, to accept the positive claim that $\mathrm{X}$ is tasty or reject the negative claim that $\mathrm{X}$ is not tasty is thus to expect to have a positive taste experience from $\mathrm{X}$; to accept the claim that $\mathrm{X}$ is not tasty or reject the claim that it is tasty is to expect not to have a positive experience from $\mathrm{X}$. Given that accepting one of these claims means rejecting the other and given AGREE/DISAGREE, DISAGREEMENT follows for tastiness claims. ${ }^{41}$

A similar story is available for likelihood judgments and likelihood claims. The core role of likelihood judgments is presumably to set our subjective probabilities for various

provides an appropriate target for assessments and potential acceptance or rejection only rarely, as speakers tend to have epistemic authority concerning their taste dispositions, leaving hearers without independent grounds for accepting or not accepting that speakers have the taste dispositions in question. For this reason, intuitions of agreement (and correctness) will typically follow the guiding function.

${ }^{39}$ In saying that we withhold claims of the form " $\mathrm{X}$ is tasty" when we think that others have different taste preferences, I am not saying that we also withhold our corresponding judgments. (For two different explanations of why explicitly relativized or first-personal taste judgments makes for a different communicative function, see Björnsson (2001, 101-03); Björnsson and Almér (2010, 26-27).)

40 This accounts for the major difference between the tastiness case and ordinary descriptive discourse: the mismatch between the judgment expressed and communicative purpose. Taste claims functions to create taste beliefs and expectations of taste experiences, but they do something weaker than assert that others will have the relevant experiences. (To see why the assertoric content of ordinary tastiness claims cannot plausibly be "all of us [in this conversation] would enjoy this", consider first that such a claim seems to require much more knowledge about one's audience than does "this is tasty", and, second, that if this were the content, the fact that one judge, A, doesn't like an item should provide another, B, with grounds for rejecting C's claim that the item is tasty, which it clearly doesn't: in normal conversational settings, B has such a ground only if B thinks that she doesn't like it.)

41 The idea that agreement and disagreement about taste should be understood in terms of the communicative function of taste claims is very similar to Egan's (2010) proposal. 
possibilities - high for possibilities we judge likely; low for those we judge not likely - thus affecting the amount of cognitive, emotional and physical work that we invest in these possibilities. The suggestion now is that the characteristic communicative function of likelihood claims (i.e. declarative expressions of likelihood judgments) is to produce the corresponding likelihood judgments in hearers, i.e. likelihood judgments that would typically set (roughly) the same subjective probabilities. A practice with claims performing this function makes good sense when speakers often enough have better information about the matter at hand and have thought more about the issue than have hearers. Unless speakers have weighed the evidence erroneously, or hearers have relevant evidence that speakers have not taken into account, hearers can improve their epistemic situation by adopting the corresponding subjective probabilities, now based on evidence that includes the speaker's claim. ${ }^{42}$ Moreover, this practice would not only make sense, but seems to be our actual practice. It is clear that hearers often respond in the relevant way to likelihood claims. It is also clear that speakers adjust their utterances in ways relevant to this function, expressing their likelihood judgments when epistemic guidance is needed and withholding or making explicitly subjective their likelihood claims when they have specific reasons to think that others have more information about the case at hand ("He is likely to be in the orchard, I think, but Claudia knows more").

Assume, as seems overwhelmingly reasonable, that this is the characteristic communicative function of likelihood claims. Given ACCEPT/REJECT, to accept the claim that $\mathrm{X}$ is likely or reject the claim that $\mathrm{X}$ is not likely is then to judge that $\mathrm{X}$ is likely; to accept the claim that $\mathrm{X}$ is not likely or reject the claim that $\mathrm{X}$ is likely is to judge that it is not likely. Given AGREE/DISAGREE, DISAGREEMENT follows for likelihood claims. ${ }^{43}$

It seems, then, that AGREE/DISAGREE can account for the relevant phenomena both in ordinary descriptive discourse and in the case of tastiness and likelihood claims, given independently plausible ascriptions of characteristic communicative functions to these claims. This adds to the antecedent plausibility of the postulated connection between agreement, disagreement, and communicative function.

\footnotetext{
${ }^{42}$ Recently, a number of people have tried to analyze epistemic modals in terms of communicative function. See especially Willer's recent (2013) proposal to understand them in terms of their context change potential and Björnsson and Finlay's (2010) proposal to understand epistemic relativity in deontic modals in terms of the practical function (cf. Lennertz (2014)). See also Montminy's (2012) suggestion that claims of the form it might be that $p$ have as their main communicative function to "weakly suggest" p, and that acceptance, rejection, and assessments targets this "suggestive".

${ }^{43}$ More generally, the suggestion that the function of epistemic modals is to guide likelihood judgments setting subjective probabilities within an epistemic situation, seems to explain many of the problem cases that von Fintel and Gillies (2008) raise against assessor relativist accounts of epistemic modals.
} 


\section{Understanding GORREGTNESS, INDEPENDENGE, and NO RELATIVIZATION}

Turn now from agreement and disagreement to the sort of attributions of correctness and incorrectness (and cognates truth and falsehood, rightness and wrongness) that are directly involved in the CORRECTNESS, INDEPENDENCE, and NO RELATIVIZATION aspects of UNITY. As in the previous section, the task is to not only predict but also make sense of patterns of such attributions across domains of discourse. The key here, as in the previous section, will be an understanding of the characteristic function of the claims and judgments involved.

The account to be developed builds on the notion of a fundamental standard for judgments:

FUNDAMENTAL STANDARD: $\mathrm{S}$ is a fundamental standard for a judgment, $\mathrm{J}$, if and only if there is evidential support for $\mathrm{J}$ to the extent that, and because, there is evidence that J satisfies S.

For illustration, the fundamental standard for ordinary judgments about non-relative features of the world is presumably that they represent the world as it is, or correspond to the facts (leaving open how representation and correspondence are best understood). So, for example, there is evidential support for the judgment that Hobbes wrote Leviathan to the extent that, and because, there is evidence that the world is as represented by this judgment. Moreover, treating correspondence as the fundamental standard makes sense given that these judgments serve as our "map" of an intersubjectively accessible world, a map variously employed in theoretical and practical cognition to serve our many concerns and interests. Normally, our successful use of this map will rely on a systematic correspondence between its constituting judgments and the relevant aspects of the world.

Using the notion of a fundamental standard, I suggest that the relevant attributions of correctness and incorrectness (and cognates) work as follows:

CORRECT/INCORREGT: We find a judgment correct, right or true (incorrect, wrong or false) to the extent that we take that judgment (its contrary) to conform to the fundamental standard for such judgments. We find a claim correct, right or true (incorrect, wrong or false) to the extent that we take the sort of judgment constituting acceptance (rejection) of the claim to conform to the fundamental standard for such judgments. ${ }^{44}$

\footnotetext{
${ }^{44}$ Notice that CORRECT/INCORRECT provides no account of truth, falsehood, etc., only an account of our attributions of such properties. It should be compatible with a variety of substantive theories of truth, including minimalist theories, but it might relate in most obvious ways to theories building on the idea that truth is the goal of rational inquiry. For ways of building theories of truth on that idea and related platitudes, see Lynch (2009) and C. Wright (1992).
} 
Assume that we take correspondence to be the fundamental standard for judgments communicated in ordinary, non-relative descriptive discourse. Given CORRECT/INCORRECT, perceived correspondence will then guide attributions of correctness and incorrectness to such judgments, as well as to claims the function of which is to produce (or make occurrent) such judgments. CORRECTNESS follows straightforwardly: if $\mathrm{F}$ is a non-relative descriptive predicate and A claims that $\mathrm{X}$ is $\mathrm{F}$ while $\mathrm{B}$ claims that $\mathrm{X}$ is not $\mathrm{F}$, then if one claim is correct (true, right) the other must be incorrect (false, wrong). Likewise for INDEPENDENCE and NO RELATIVIZATION.

What I will argue now is that there are plausible stories to tell about what we should expect the operative fundamental standards to be not only for paradigmatically absolutist judgments, but also for tastiness and likelihood judgments. Given these stories, CORRECT/INCORRECT has enough substance to let us explain why CORRECTNESS, INDEPENDENCE, and NO RELATIVIZATION obtain to varying degrees for these different kinds of judgments.

Start with tastiness claims, focusing on the positive variety (" $\mathrm{X}$ is tasty", as opposed to " $\mathrm{X}$ is not tasty"). The characteristic communicative function of such claims, I have suggested, is not to bring about judgments that some non-relative state of affairs obtains, but to provide (fallible) gustatory guidance by making hearers expect that their own palates would react favorably to the item in question. Correspondingly, the fundamental standards for accepting or rejecting positive tastiness claims are standards that determine what we take to support or undermine such expectations. Clearly, we do not in general take there to be any such standards beyond the palates of the individual judges functioning under suitably normal circumstances. Given this, CORRECT/INCORRECT explains why attributions of correctness or incorrectness to tastiness claims seem off when there is reason to think that parties of the conversation will have different taste reactions to the item in question: there is no one relevant standard to appeal to in the discourse. If there is a standard to apply here, it is judge relative, leading to violations of CORRECTNESS, INDEPENDENCE, and NO RELATIVIZATION. But CORRECT/INCORRECT also explains why assessments of correctness and incorrectness seem possible in contexts where it is assumed that all involved have matching taste reactions with respect to the relevant foods: in such contexts, there is a common standard. Together with an independently plausible account of the function of tastiness clams, CORRECT/INCORRECT can thus explain both why CORRECTNESS is problematic for tastiness and why attributions of correctness and incorrectness are nevertheless possible in some contexts.

Next consider likelihood claims. Their communicative function, I have suggested, is to produce likelihood judgments that set the same subjective probabilities as the judgments expressed by the claims. By CORRECT/INCORRECT, the relevant standards for assessments of correctness, incorrectness, etc., would thus be standards for these likelihood judgments. What standards are these? In general, we think that likelihood judgments governing subjective 
probabilities should be reasonable given the evidence, and be based on more relevant evidence rather than less. This explains why we take a likelihood claim to be incorrect if we can support rejection of it with reference to evidence going beyond what is accessible to the speaker, as Claudia does in the case of FINDING FELIX. We thus have a straightforward explanation of why likelihood claims can conform to CORREGTNESS even when ABSOLUTISM is not satisfied for the judgments involved: the fundamental standards are insensitive to the information accessible to particular speakers. For the same reason, INDEPENDENCE might seem to hold: any evidence that hearers have access to, whether available to the speaker or not, might be relevant for criticizing or supporting acceptance or rejection of the claim. Likewise for NO RELATIVIZATION: To determine which likelihood judgments are supported relative to the evidence available to different judges is not yet to resolve any disagreement about whether Felix is likely to be in the orchard. This can only be done by determining which evidence is best.

What, though, of our willingness, in HINDSIGHT, to deem correct Basil's claim that Felix was likely to be in the orchard, and our reluctance to say that it was incorrect? If a likelihood claim should be rejected if our best evidence supports the contrary likelihood judgment, why do we not just reject Basil's claim? The explanation for this, I suggest, is the same as for our difficulty to judge, in HINDSIGHT, whether Felix was likely to be in the orchard. Since the function of ordinary, unrelativized, likelihood judgments is to guide our subjective probabilities for a proposition, they have no place once we take the truth value of that proposition for granted. Relatedly, likelihood claims having as their characteristic communicative function to produce likelihood judgments have no such function in relation to hearers who already know the truth value of that proposition. The correctness of such claims must thus be assessed in relation to some other epistemic perspective than that of HINDSIGHT knowledge. Since the most salient such perspective when considering the correctness of Basil's claim will be Basil's own, we are naturally led to think about whether accepting the claim would satisfy the standards relative to the information available in that perspective. ${ }^{45} \mathrm{Of}$ course, the same holds, mutatis mutandis, for our assessments of Claudia's claim that Felix was not likely to be in the orchard. So CORRECTNESS is violated, and, by extension, so are INDEPENDENCE and NO RELATIVIZATION.

45 Cf. Björnsson and Almér (2010); Björnsson and Finlay (2010, 23). As noted for other epistemic modals, related phenomena are displayed within a conversation when it is common knowledge that one of the parties has more information but will not share it (von Fintel and Gillies (2008, 90); Björnsson and Almér (2010, 31-32). 


\section{Prospects for a non-ABSOLUTIST account of moral UNITY}

Thus far I have proposed ways of understanding disagreement and attributions of correctness that are independently motivated and seem to capture the extent to which UNITY is satisfied in paradigmatically ABSOLUTE domains as well as in the case of tastiness and likelihood judgments. Since space prevents a fuller defense of these proposals, my objective here has been more modest: to present and provide initial motivation of a principled ground for assessing non-ABSOLUTIST explanations of UNITY in the moral domain.

Suppose that AGREE/DISAGREE and CORREGT/INCORRECT are indeed on the right track. Then a non-ABSOLUTIST explanation of moral UNITY requires two things. First, it requires that moral claims have a characteristic communicative function such that judgments constituting acceptance of these claims can differ in their internal success conditions. If they do, people's agreement and disagreement on moral issues do not depend on absolutism. Second, it requires that people take fundamental standards for moral judgments to have consistent content and apply equally across moral judgments, independent of variations in the internal success conditions, and independently of assessors' own relations to the judges. If people do, this would be sufficient, independently of absolutism, for people to attribute correctness and incorrectness along the pattern of CORRECTNESS, while taking INDEPENDENCE and NO RELATIVIZATION to be satisfied.

Both requirements seem well within the realm of the possible. Consider the first. Although few defend stronger forms of motivational internalism, it should be much less controversial that moral claims have as their characteristic communicative function to bring about or make occurrent judgments with a certain practical role. For example, it seems plausible that claims of moral wrongness have as their characteristic communicative function to bring about or make occurrent judgments that dispose judges to negative social emotions towards the agent. Likewise, it seems reasonably plausible that claims of what ought to be done under certain circumstances, all things considered, have as their characteristic function to bring about or make occurrent plans to act accordingly. Neither of these functional hypotheses requires any strong form of motivational internalism. What is required is merely that we have default expectations that these claims are made in order that hearers make judgments with certain practical roles, and that these expectations are embodied in our default patterns of acceptance and rejection. ${ }^{46}$ Moreover, it seem at least possible that moral

\footnotetext{
${ }^{46}$ This assumption is in line with recent empirical studies of internalist intuitions among lay people (see Björnsson et al. (2014)) but should be compatible even with strong externalist views, such as those of Strandberg (2012) and Svavarsdottir (1999); (2006). Practical roles might include not only being for or against something, but also states of preferential neutrality, either all-considerations-considered, or allmoral-considerations-considered (see Dreier (2006); (2009); Silk (forthcoming)).
} 
claims have these practical functions even though internal success conditions for moral judgments vary among moral judges. The lack of agreement - extensional or intensional - on substantial characterizations of moral properties provides prima facie evidence that internal success conditions do in fact vary, and it seems undeniable that we need coordination of attitudes between people not antecedently committed to the same practical standards.

The second requirement seems equally surmountable. Non-absolutism itself says nothing about how we conceive of the fundamental standards against which we assess moral judgments, and forms of relativism and non-cognitivism seem compatible in principle with the assumption that we conceive of such standards as invariant across judges and judgments. In fact, if moral discourse and moral thinking are shaped to support the coordination of attitudes through the coordination of moral judgments, as non-absolutists have often suggested, ${ }^{47}$ such invariance in standards for judgments might be an important regulative ideal.

At least at a first glance, then, AGREE/DISAGREE and CORRECT/INCORRECT seem to leave room for non-ABSOLUTIST explanations of moral UNITY. Interestingly, they also suggest reasons why the moral domain might not display UNITY to the fullest extent. One possibility, for example, is that people understand the characteristic function of moral claims as restricted to an audience within the speaker's society, roughly in the way that the function of likelihood claims might be restricted to an audience sharing the same epistemic predicament. If people do, they should find DISAGREEMENT problematic when considering the moral claims and judgments of people in other societies. Another possibility, suggested by the case of HINDSIGHT, is that some people see fundamental standards as relative in various ways, or apply different standards depending on whose judgment is being assessed, perhaps depending on the society in which it is made. People who do might reject CORRECTNESs and INDEPENDENCE while thinking that DISAGREEMENT holds. 48 AGREE/DISAGREE and CORRECT/INCORRECT thus provide tools given which UNITY can be systematically explained in non-ABSOLUTIST discourse to the extent that it is actually there.

Of course, to say that some form of non-absolutism can explain UNITY in the moral domain is not to say that there is one that actually does. For all I have said, absolutism might be true, and both relativist and non-cognitivist accounts might ultimately succumb to objections other than the argument from UNITY. If what I have said here is correct, however, and if AGREE/DISAGREE and CORRECT/INCORREGT are on the right track, a systematic, independently motivated and non-ad hoc account of moral UNITY is in the offing. This is an interesting enough prospect to merit further consideration.

\footnotetext{
47 See e.g. Björnsson and McPherson (2014); Blackburn (1993b); Gibbard (1990).

48 The folk intuitions canvassed by Sarkissian et al. (2011) might reveal such an understanding.
} 


\section{Bibliography}

Almér, Alexander and Björnsson, Gunnar 2009. "Contextualism, Assessor Relativism, and Insensitive

Assessments". Logique et Analyse, 52, 363-72.

Björklund, Fredrik, Björnsson, Gunnar, Eriksson, John, Francén Olinder, Ragnar and Strandberg, Caj

2012. "Recent Work on Motivational Internalism". Analysis, 72, 124-37.

Björnsson, Gunnar 2001. "Why Emotivists Love Inconsistency”. Philosophical Studies, 104, 81-108.

Björnsson, Gunnar 2012. "Do 'Objectivist' Features of Moral Discourse and Thinking Support Moral Objectivism?". The Fournal of Ethics, 16, 367-93.

Björnsson, Gunnar 2013: 'Quasi-Realism, Absolutism, and Judgment-Internal Correctness

Conditions'. In Fohanssonian Investigations: Essays in Honour of Ingvar Fohansson on His Seventieth Birthday.

Svennerlind, Christer, Almäng, Jan and Ingthorsson, Rögnvaldur (eds) Ontos, 96-119.

Björnsson, Gunnar ms: 'Discursivism About Disagreement in Attitude'.

Björnsson, Gunnar and Almér, Alexander 2010: 'The Pragmatics of Insensitive Assessments:

Understanding the Relativity of Assessments of Judgments of Personal Taste, Epistemic Modals,

and More'. In Formal Semantics and Pragmatics. Discourse, Context and Models. Manhattan, Ks: New Prairie Press, Pp. 1-45. Partee, B.H., Glanzberg, M., \& Skilters, J. (ed).

Björnsson, Gunnar, Eriksson, John, Strandberg, Caj, Olinder, Ragnar Francén and Björklund, Fredrik

2014. "Motivational Internalism and Folk Intuitions". Philosophical Psychology, 1-20.

Björnsson, Gunnar and Finlay, Stephen 2010. "Metaethical Contextualism Defended". Ethics, 121, 736.

Björnsson, Gunnar and McPherson, Tristram 2014. "Moral Attitudes for Non-Cognitivists: Solving the Specification Problem". Mind, 123, 1-38.

Blackburn, Simon 1984: Spreading the Word. Oxford: Oxford U. P.

Blackburn, Simon 1991a. "Just Causes". Philosophical Studies, 61, 3-17.

Blackburn, Simon 1991b. "Reply to Sturgeon's "Contents and Causes: A Reply to Blackburn"”. Philosophical Studies, 39-42.

Blackburn, Simon 1993a: Essays in Quasi-Realism. Oxford: Oxford U. P.

Blackburn, Simon 1993b: 'How to Be an Ethical Anti-Realist'. In Essays in Quasi-Realism. Blackburn, Simon (ed) Oxford: Oxford U. P., 166-81.

Brink, David O. 1989: Moral Realism and the Foundations of Ethics. Cambridge: Cambridge U. P.

Buekens, Filip 2011. "Faultless Disagreement, Assertions and the Affective-Expressive Dimension of Judgments of Taste". Philosophia, 39, 637-55.

Doerfler, Ryan 2012. "A Comedy of Errors or, How I Learned to Stop Worrying and Love Sensibility-Invariantism About 'Funny”. Pacific Philosophical Quarterly, 93, 493-522.

Dowell, Janice 2011. "A Flexibly Contextualist Account of Epistemic Modals". Philosopher's Imprint, 11, $1-25$. 
Dreier, James 2006. "Negation for Expressivists: A Collection of Problems with a Suggestion for Their Solution". Oxford Studies in Metaethics, 1, 217-33.

Dreier, James 2009. "Relativism (and Expressivism) and the Problem of Disagreement". Philosophical Perspectives, 23, 79-110.

Egan, Andy 2007. "Epistemic Modals, Relativism and Assertion". Philosophical Studies, 133, 1-22.

Egan, Andy 2010: 'Disputing About Taste'. In Disagreement. Warfield, Ted and Feldmans, Richard (eds) Oxford University Press.

Finlay, Stephen 2014: Confusion of Tongues: A Theory of Normative Language. Oxford University Press.

Gibbard, Allan 1990: Wise Choices, Apt Feelings. Cambridge MA: Harvard U. P.

Gibbard, Allan 2003: Thinking How to Live. Cambridge, MA: Harvard U. P.

Glanzberg, Michael 2007. "Context, Content, and Relativism”. Philosophical Studies, 136, 1-29.

Goodwin, Geoffrey P. and Darley, John M. 2008. “The Psychology of Meta-Ethics: Exploring Objectivism". Cognition, 106, 1339-66.

Hare, Richard M. 1970. "Meaning and Speech Acts". The Philosophical Reviewe, 79, 3-24.

Huemer, Michael 2005: Ethical Intuitionism. Palgrave Macmillan.

Knobe, Joshua and Yalcin, Seth forthcoming. "Epistemic Modals and Context: Experimental Data". Semantics and Pragmatics.

Kölbel, Max 2004. "Faultless Disagreement". Proceedings of the Aristotelian Society (Hardback), 104, 53-73.

Lasersohn, Peter 2005. "Context Dependence, Disagreement, and Predicates of Personal Taste". Linguistics and Philosophy, 28, 643--86.

Lennertz, Benjamin 2014. "Taking 'Might'-Communication Seriously”. Analytic Philosophy, 55, 176-98.

Loeb, Don 2003. "Gastronomic Realism - a Cautionary Tale". The Fournal of Theoretical and Philosophical Psychology, 23, 30-49.

Lynch, Michael P. 2009: Truth as One and Many. Oxford: Clarendon Press.

Lyons, David 1976. "Ethical Relativism and the Problem of Incoherence". Ethics, 86, 107-21.

MacFarlane, John 2011: 'Epistemic Modals Are Assessment-Sensitive'. In Epistemic Modality. Egan, Andy and Weatherson, Brian (eds) Oxford University Press.

McKenna, Robin 2014. "Disagreeing About 'Ought”. Ethics, 124, 589-97.

McNaughton, David 1988: Moral Vision: An Introduction to Ethics. Oxford: Blackwell.

Millikan, Ruth Garrett 1984: Language, Thought, and Other Biological Categories: New Foundations for Realism. Cambridge, MA: MIT Press.

Millikan, Ruth Garrett 1998. "Language Conventions Made Simple". Fournal of Philosophy, 95, 161-80.

Montminy, Martin 2012. "Epistemic Modals and Indirect Weak Suggestives". Dialectica, 66, 583-606.

Pearson, Hazel 2012. "A Judge-Free Semantics for Predicates of Personal Taste". Fournal of Semantics.

Plunkett, David and Sundell, Timothy 2013. "Disagreement and the Semantics of Normative and Evaluative Terms". Philosopher's Imprint, 13, 1-37. 
Ridge, Michael 2013. "Disagreement”. Philosophy and Phenomenological Research, 86, 41-63.

Sarkissian, Hagop, Park, John, Tien, David, Wright, Jennifer and Knobe, Joshua 2011. "Folk Moral Relativism". Mind and Language, 26, 482-505.

Sayre-McCord, Geoffrey 2006: 'Moral Realism'. In The Oxford Handbook of Ethical Theory. Copp, David (ed) Oxford: Oxford U. P., 39-62.

Schaffer, Jonathan 2011: 'Perspective in Taste Predicates and Epistemic Modals'. In Epistemic Modality. Egan, Andy and Weatherson, Brian (eds) Oxford University Press, 179-226.

Shafer-Landau, Russ 2003: Moral Realism: A Defence. Oxford U. P.

Silk, Alex forthcoming. "How to Be an Ethical Expressivist". Philosophy and Phenomenological Research.

Smith, Michael 1994: The Moral Problem. Oxford: Basil Blackwell.

Stalnaker, Robert 1999: Context and Content: Essays on Intentionality in Speech and Thought. Oxford University Press.

Stalnaker, Robert 2002. "Common Ground”. Linguistics and Philosophy, 25, 701-21.

Stephenson, Tamina 2007. "Judge Dependence, Epistemic Modals, and Predicates of Personal Taste". Linguistics and Philosophy, 30, 487-525.

Stevenson, Charles L. 1944: Ethics and Language. New Haven: Yale University Press.

Stevenson, Charles L. 1963: Facts and Values: Studies in Ethical Analysis. New Haven: Yale University Press.

Strandberg, Caj 2012. "A Dual Aspect Account of Moral Language”. Philosophy and Phenomenological Research, 84, 87-122.

Street, Sharon 2006. "A Darwinian Dilemma for Realist Theories of Value”. Philosophical Studies, 127, 109-66.

Streiffer, Robert 2003: Moral Relativism and Reasons for Action. Routledge.

Sturgeon, Nicholas L. 1991. "Contents and Causes: A Reply to Blackburn". Philosophical Studies, 61, 1937.

Sundell, Timothy 2011. "Disagreements About Taste". Philosophical Studies, 155, 267-88.

Svavarsdóttir, Sigrún 1999. "Moral Cognitivism and Motivation". The Philosophical Reviewe, 108, 161219.

Svavarsdóttir, Sigrún 2006: 'How Do Moral Judgments Motivate'. In Contemporary Debates in Moral Theory. Dreier, James (ed) Blackwell, 163-81.

Swanson, Eric 2011: 'How Not to Theorize About the Language of Subjective Uncertainty'. In Epistemic Modality. Egan, Andy and Weatherson, B. (eds) Oxford University Press, 249-69.

Tersman, Folke 2006: Moral Disagreement. Cambridge U. P.

von Fintel, Kai and Gillies, Anthony S. 2008. "Cia Leaks". Philosophical Review, 117, 77-98.

Willer, Malte 2013. "Dynamics of Epistemic Modality". Philosophical Review, 122, 45-92.

Wright, Crispin 1992: Truth and Objectivity. Cambridge, Mass.: Harvard University Press. 
Wright, Jennifer C., Grandjean, Piper T. and McWhite, Gullen B. 2012. "The Meta-Ethical Grounding of Our Moral Beliefs: Evidence for Meta-Ethical Pluralism". Philosophical Psychology, 26, $336-61$.

Wright, Jennifer C., McWhite, Cullen B. and Grandjean, Piper T. in press: 'The Cognitive Mechanisms of Intolerance: Do Our Meta-Ethical Commitments Matter?'. In Oxford Studies in Experimental Philosophy, Vol 1. Lombrozo, Tania, Nichols, Shaun and Knobe, Joshua (eds).

Young, Liane, Nichols, Shaun and Saxe, Rebecca 2010. "Investigating the Neural and Cognitive Basis of Moral Luck: It's Not What You Do but What You Know". Review of Philosophy and Psychology, 1, $333-49$. 